\title{
$O$ reaparecimento da homossexualidade masculina nas estratégias de prevenção da infecção por HIV: reflexôes sobre a implementação da PrEP no Brasil
}

I ${ }^{1}$ Luiz Fernando Greiner Barp, ${ }^{2}$ Myriam Raquel Mitjavila I

Resumo: Este trabalho toma como ponto de partida o texto de Nestor Perlongher, intitulado "O desaparecimento da homossexualidade", que descreve um esvaziamento da identidade homossexual masculina com o surgimento da aids e propóe uma nova leitura a partir da implementação da profilaxia pré-exposição ao HIV (PrEP) pelo sistema público de saúde no Brasil. Distribuída a partir do início de 2018 e considerada como uma das mais novas medidas de prevenção ao HIV/aids, a PrEP se configura como um esquema antirretroviral de uso contínuo direcionado aos sujeitos que não foram infectados pelo vírus. Tomando como referência empírica o Protocolo Clínico de Diretrizes Terapêuticas para PrEP, identificamos como, a partir da noção de risco, a profilaxia possibilita o retorno da homossexualidade aos consultórios médicos e, mais do que isso, opera como objeto discursivo de problematizaçóes de caráter sanitário e social. Diante disso, a PrEP produz uma nova categoria de homossexual, atrelada a tecnologias disciplinares e biopolíticas, que se apoiam na individualização e responsabilização dos indivíduos pelo cuidado de si.

> Palavras-chave: homossexualidade; HIV; PrEP; risco; individualização.

\footnotetext{
${ }^{1}$ Universidade Federal de Santa Catarina. Florianópolis-SC, Brasil (barp.If@gmail.com). ORCID: 0000-0001-5256-8712

2 Universidade Federal de Santa Catarina. Florianópolis-SC, Brasil (myriammitjavila@gmail.com). ORCID: 0000-0002-2686-7986
}

Recebido em: 01/06/2019 Aprovado em: 23/11/2019 Revisado em: 30/08/2020 


\section{Introdução}

Sentada na mesa de um bar, a dama da noite conversa com um jovem rapaz e narra seus bons e livres momentos vividos entre os anos 60 e 70. Ao mesmo tempo que, nostálgica, sente falta do passado marcado pela liberdade sexual, lamenta as proibiçôes sociais que atingiram principalmente os mais jovens com a chegada da década de 80 e, junto dela, a epidemia da aids. Imersa em um monólogo interior, a personagem típica da cena underground de uma grande metrópole brasileira utiliza do sarcasmo e de um vocabulário impudico para lamentar a morte do que seria um sexo livre, sem medo e sem prevenção.

\footnotetext{
Você não viu nada, você nem viu o amor. Que idade você tem, vinte? Tem cara de doze. Já nasceu de camisinha em punho, morrendo de medo de pegar Aids. Vírus que mata. neguinho, vírus do amor. Deu a bundinha, comeu cuzinho, pronto: paranoia total. Semana seguinte, nasce uma espinha na cara e salve-se quem puder: baixou Emílio Ribas. Caganeira, tosse seca, gânglios generalizados. Ô boy, que grande merda fizeram com a tua cabecinha, hein? Você nem beija na boca sem morrer de cagaço. Transmite pela saliva, você leu em algum lugar. Você nem passa a mão em peito molhado sem ficar de cu na mão. Transmite pelo suor, você leu em algum lugar. Supondo que você lê, claro. Conta pra tia: você lê, meu bem? Nada, você náo lê nada. Você vê pela tevê, eu sei. Mas na tevê também dá, o tempo todo: amor mata. Pega até de ficar do lado, beber do mesmo copo. Já pensou se eu tivesse? Eu, que já dei pra meia cidade e ainda por cima adoro veado (ABREU, 1988, p. 92-93).
}

Entre uma bebida e outra, a dama da noite ironiza as consequências que a aids trouxe para o sexo, passando da paranoia aos gânglios generalizados. Afirma que tem pena das novas geraçôes, que nem sequer puderam experimentar a sensação da revolução sexual. Informadas pela televisão, os jovens agora vivenciavam o pânico. Nas suas palavras, quando nasceram tudo já estava morto, isto é, não havia mais tranquilidade, orgasmo livre, gozo farto. $\mathrm{O}$ desejo deu lugar ao medo.

Personagem de um dos contos do escritor Caio Fernando de Abreu que compóem o livro Os dragóes não conhecem o paraíso, publicado em 1988 e vencedor do prêmio Jabuti do mesmo ano, não há certeza de que a dama da noite de fato existiu. Contudo, se recorremos à ficção é porque encontramos nela um retrato da penumbra que a aids trouxe consigo, principalmente aos homossexuais homens. Por ironia ou não, o próprio criador da dama da noite - homossexual assumido - morreu devido a complicaçôes do que seria um "vírus gay". Embora vítima do que contavam suas próprias palavras, Caio deixou uma vasta literatura que aborda a epidemia e conduz seus últimos escritos. 
É fato que hoje já podemos afirmar que as memórias da dama da noite não se restringem à criaçáo autoral de uma literatura ficcional. $\mathrm{O}$ conto não deixa de ser uma crítica aos tantos dilemas que a epidemia da aids acionou enquanto fenômeno social. Quando afirma que seu interlocutor não viu o amor, pois já nasceu com a camisinha em punho, a personagem demarca uma nova maneira de encarar o sexo. Maneira muito semelhante àquela que levou o antropólogo Néstor Perlongher a decretar o desaparecimento da homossexualidade em um texto publicado em 1993. Não o fim em termos biológicos, embora muitos homossexuais masculinos tenham morrido em decorrência da aids, mas o fim de suas condutas. Dá liberdade à sanção, do liberto apogeu à punição. Há de se considerar, contudo, que passados mais de 30 anos desde que os primeiros casos de aids foram notificados no Brasil, o cenário criado em torno da epidemia em muito mudou. Com a criação de políticas públicas voltadas ao HIV/aids, a inclusão de medicamentos e outros métodos preventivos, a doença deixou de ser letal e adquiriu uma característica crônica.

Tendo em vista esse contexto recente, a partir de uma perspectiva foucaultiana, em diálogo com a sociologia do risco e os estudos de gênero, propomos neste trabalho uma atualização do texto de Néstor Perlongher, tomando como objeto o surgimento da profilaxia pré-exposição ao HIV (PrEP). Trata-se de um medicamento gratuito, disponível a partir do início de 2018 pelo sistema público de saúde no Brasil, e que se destina aos que desejam se proteger do vírus HIV e, consequentemente, da aids. Produzido pela farmacêutica Gilead, define-se pela combinação dos antirretrovirais tenofovir e emtricitabitina, sendo também chamado pelo nome comercial Truvada, e que deve ser ingerido diariamente como método preventivo (BRASIL, 2017).

Nesse sentido, este trabalho está dividido em duas seçóes. $\mathrm{Na}$ primeira, apresentamos um percurso do que poderíamos caracterizar, nos termos de Perlongher, de aparecimento e desaparecimento da homossexualidade masculina. Em seguida, tomando como objeto empírico o Protocolo Clínico de Diretrizes Terapêuticas para PrEP - documento que institucionaliza a implantaçáo do medicamento -, analisamos o que chamamos de reaparecimento da homossexualidade, isto é, um novo homossexual masculino que nasce sob a luz das recentes estratégias de prevenção da infecção por HIV. 


\section{Do pecado à doença}

Conectando-a às condiçôes de sua produção, isto é, identificando as relaçôes e práticas que a investem, é possível entender um pouco mais sobre a homossexualidade masculina moderna. Afinal, assim como diferentes foram suas maneiras de se exercer ao longo dos séculos, distintas também foram as restriçôes, sançôes e exigências dirigidas a ela e seus efeitos sobre a população. Diante da evidente associação entre homossexualidade e prática sexual, consideramos pertinente inseri-la no contexto do que Michel Foucault nomeou como História da Sexualidade.

Nesse sentido, embora defendamos que não haja nenhuma verdade absoluta sobre o que é a homossexualidade e que as ideias e práticas a ela associadas são produzidas historicamente (FRY; MACRAE, 1985), dedicaremos parte desta seçáo para discutir como a medicina cria e se apropria da prática homossexual para exercer certas açóes de controle social. Dito de outro modo, como a enunciação médica possibilita boa parte da construção social do que seria a homossexualidade masculina moderna, passando do pecado à doença.

Como destaca Perlongher (1987), a homossexualidade mantém certa "dívida" com a medicina, pois coube a ela inventar e organizar seus modos de nominação e implantação. Foi o médico húngaro Karoly Maria Benkerdsua que definiu pela primeira vez o termo homossexual. A expressão surgiu em 1869, em substituição ao poético uranista, assumindo uma conotação estritamente clínica que servia para descrever a realidade das pessoas que tinham um impulso sexual voltado para alguém do seu mesmo sexo biológico. Em termos retóricos, seu surgimento enfraquece o domínio teológico da sodomia, onde até então a Igreja situava os sujeitos que desenvolviam um interesse sexual considerado "perverso" (PERLONGHER, 1987).

Sustentada pela ideia de que a saúde estaria diretamente relacionada com o controle da sexualidade, a medicina então toma o lugar da Igreja e assume a autoridade de falar a verdade sobre homossexualidade. Um dos médicos pioneiros a desenvolver estudos sobre esses sujeitos, o australiano Krafft-Ebing, na intenção de enfatizar os aspectos biológicos e inatos da homossexualidade, caracterizou-a como uma patologia congênita, capaz de causar condiçôes de degeneração mental, tais como a imbecilidade e loucura moral (FRY; MACRAE, 1985).

Ocorre que, uma vez definida como patologia, buscou-se também encontrar suas causas, que passaram a ser explicadas tanto por bases biológicas (defeitos congênitos, hereditariedade, defeitos hormonais), quanto em termos de meio social, ou mesmo 
pela interação entre ambas. E diante do diagnóstico, também se abriu a possibilidade de tratamento, como lembram Fry e Macrae (1985, p. 66) a respeito do que propunha o médico brasileiro Leonidio Ribeiro:

Nos casos dos indivíduos cuja homossexualidade é resultante do meio ambiente, propóe-
-se "medidas pedagógicas. [...] Em muitos casos, sobretudo quando está em jogo o filho
único, em que a predominante a influência materna, a solução será o afastamento do
ambiente familiar, a fim de que a criança possa privar com pessoas de sua idade e de sexo
contrário. [...] É preciso suprimir os carinhos e facilidades do ambiente familiar. [...] Em
tais casos a inútil a internaçáo em colégios onde haja dormitórios coletivos, sem fiscaliza-
çáo rigorosa, na convivência exclusiva com crianças do mesmo sexo.

Esses fatos dialogam com o nascimento do que Foucault (2017) chamou de scientia sexualis, isto é, a multiplicação dos discursos sobre o sexo, subordinados aos imperativos de uma moral, e que aparecem a partir do século XVIII sobre forma de normas médicas. Destaca o filósofo francês que com o fim da fome e das epidemias na Europa, a população se tornou um problema econômico e político. Diante disso, os governos começaram a perceber os indivíduos não mais isoladamente, mas sim como uma coletividade que necessitava de estratégias de equilíbrio para garantir a ordem e a produtividade. Na medida em que para administrar a população é preciso manter um controle sobre as taxas de natalidade e fecundidade, a sexualidade passou a ser administrada por mecanismos sutis, pois se situa exatamente no limite entre o biológico e o econômico. Cabe dizer, então, que "entre o Estado e o indivíduo, o sexo tornou-se objeto de disputa, e disputa pública; toda uma teia de discursos, de saberes, de análise e de injunçóes o investiram" (FOUCAULT, 2017, p. 30).

Nesse cruzamento entre os saberes sobre o sexo e a incidência deles sobre os indivíduos, o prazer sexual se torna palco do agenciamento concreto de disciplinas e regulamentaçôes biopolíticas, ${ }^{1}$ ou seja, de tipos de poderes específicos que regulamentam o corpo e o desejo, visando à criação de uma norma histórico-social. A partir das estratégias que se desenvolvem em torno dos processos de normalização disciplinar e biopolítica, o poder unitário e repressivo dá lugar a um poder que se estilhaça em efeitos produtivos sobre os corpos e populações. O saber médico, de acordo com Foucault (2010, p. 212), entrelaça-se nessa relação que une o poder com a sexualidade dos sujeitos:

[...] dado o vínculo que estabelece entre as influências científicas sobre os processos biológicos e orgânicos (isto é, sobre a população e sobre o corpo) e, ao mesmo tempo, na medida em que a medicina vai ser uma técnica política de intervençáo, com efeitos de poder próprios. 
Há de se ressaltar, portanto, que se no Brasil, durante a era colonial (1530-1822), a prática da homossexualidade foi tratada como um pecado hediondo, provocador da ira de Deus (FRY; MACRAE, 1985), a partir da irrupçâo da medicina como tutora dessas práticas, o que se percebe é uma intervenção mais sutil na vida desses sujeitos, mas que nem por isso se torna menos incisiva, uma vez que intervém tanto sobre o orgânico quanto sobre o seus regimes de vida.

Não se pode falar, é claro, que a medicina conseguiu dar fim a homossexualidade, no sentido de impor a conversão dos indivíduos segundo um modelo heterossexual. Embora médicos tenham defendido a possibilidade de "cura", o que se viu foi muito mais uma proliferação de saberes e poderes sobre o sexo "anormal", que acarretaram o próprio crescimento dessa "perversão" (PERLONGHER, 1987). Aceitando que não há poder sem resistência (FOUCAULT, 2014), a multiplicação desses saberes e poderes em muito contribuiu para o surgimento de uma "consciência homossexual", isto é, para o surgimento de movimentos ativistas organizados que reivindicaram a gradativa despatologização da homossexualidade.

A Associação Americana de Psiquiatria deixou de considerá-la doença em 1973. Em 1985 foi a vez do Conselho Federal de Psicologia no Brasil. Já em 1992, a Organização Mundial da Saúde (OMS) recomendou que a homossexualidade não deveria mais ser considerada uma doença. E, embora cada país ainda tenha autonomia para tratar essa questão à sua maneira, desde 1990 a Classificaçáo Internacional de Doenças (CID) deixou de considerá-la doença e/ou transtorno, sendo consolidada sua despatologização em 1994, com a publicação da quarta edição do Manual Diagnóstico e Estatístico de Transtornos Mentais (DSM-IV).

Registros de médicos que deixaram de defender a "cura" da homossexualidade, contudo, são identificados desde a década de 70. A publicação do livro $A$ sociedade e o homossexual sadio (1973), do médico americano George Wainberg, é um exemplo representativo do surgimento de médicos mais "progressistas", que recusavam a conversão do homossexual em heterossexual. Como destacam Fry e Macrae (1985), o que se passa a defender, como sugere o título da obra de Wainberg, é que os homossexuais aceitem felizmente essa "condição":

Um homossexual é gay quando ele se vê feliz de ser alguém dotado da capacidade de enxergar as pessoas como romanticamente belas. Ser gay é ser livre de vergonha, culpa e remorso de ser homossexual. [...] Ser gay a vislumbrar sua sexualidade como o heterossexual sadio enxerga a dele. (WEINBERG, 1973, apud FRY; MACRE, 1985, p. 77). 
Se em termos de conversão nunca foi possível controlar a homossexualidade com tratamentos médicos, o aparecimento de uma doença que incide diretamente no desejo sexual mudou decisivamente o seu panorama. Coincidentemente ou não, no mesmo período em que diferentes partes do mundo ocidental assumiram que a homossexualidade não era uma doença, a descoberta do vírus HIV e as mortes por aids atacaram no âmago dessa sexualidade desviante.

As primeiras notificaçôes da doença, nos centros de investigação epidemiológica da França e EUA, no início dos anos 80, não somente instalaram um pânico coletivo como também contribuíram para a imediata associação entre a aids e a homossexualidade. Em grande medida, isso ocorreu pela criação e divulgação da expressão "grupos de risco", popularmente conhecidos como cinco Hs: homossexuais, hemofílicos, haitianos, heroinômanos e hookers (nome dado em inglês às profissionais do sexo) que, por conta de suas identidades, foram apontados pela epidemiologia como mais propensos a se infectar (AYRES, 2003).

O Brasil, embora ainda náo tivesse notificado nenhum caso de aids nos primeiros anos, ${ }^{2}$ assume essa narrativa internacional e publica, em um dos principais veículos de comunicação, já em 1981, a reportagem intitulada "Câncer em homossexuais é pesquisado nos Estados Unidos” (GALVÃO, 2002). A ideia de câncer, peste ou praga gay, portanto, irrompe na mídia brasileira antes mesmo da publicação de qualquer boletim epidemiológico. Esse motivo leva o escritor, sociólogo e ativista Herbet Daniel a afirmar que a aids chegou ao Brasil antes mesmo da aids (DANIEL; PARKER, 1991).

Em um período ainda sem literatura médica ou qualquer iniciativa governamental, a mídia nacional foi a responsável por iniciar a construção de um imaginário social que associava a aids com a homossexualidade. Tomando como fonte o que era publicado nos EUA, também começa a publicar a reação à doença entre leigos, médicos e os poucos grupos organizados de homossexuais no país, na maioria das vezes de forma estereotipada e preconceituosa (BESSA, 2002).

Quando a aids desembarcou de fato no país, o imaginário social não somente estava construído como foi consolidado com a medicina que, sem muitos recursos e ainda muito despreparada para lidar com a epidemia, chegava a sugerir a abstinência ou a redução no número de parceiros sexuais (PERLONGHER, 1987). Baseando-se em um princípio probabilístico de risco, alegava que os mais promíscuos estavam mais propensos a se infectar. Mais do que isso, direcionava 
parte das orientaçóes aos homossexuais masculinos, sugerindo se absterem do coito anal e do contato com o esperma.

Se por um lado parte da sociedade se empenhou em ligar a aids com a homossexualidade, quase que imediatamente investigaçóes sociais questionavam essa associação. Em um livro intitulado $O$ que é aids, em que tanto informa sobre o vírus e a doença quanto questiona a interferência médica, Perlongher (1987, p. 92) chega a sugerir que "[...] se a aids não existisse, precisaria ser inventada". No domínio discursivo em que poder e saber se entrelaçam, incidindo sobre o corpo e o coletivo, torna-se inevitável questionar o papel da medicina que, na mesma época que emancipa a homossexualidade com sua despatologização, associa os homossexuais com uma doença mortífera e sem cura. É como se novamente o domínio da perversão voltasse aos consultórios, agora não mais em busca de conversão, mas sobre o risco de morrer.

E se não morreu, pelo menos desapareceu. Assim é que Perlongher (1993) avalia a condição da homossexualidade uma década após a epidemia da aids ser instaurada. Mas também esclarece:

[...] o que desaparece não é tanto a prática das uniões dos corpos do mesmo sexo genital,
neste caso corpos masculinos (e da paródia, denegação e roçamento de esta dada - no
sentido de dom - masculinidade trata bastante seu imaginário), mas a festa do apogeu, o
interminável festejo da emergência à luz do dia, no que foi considerado o maior aconteci-
mento do século XX: a saída da homossexualidade à luz resplandecente da cena pública,
os clamores esplêndidos do - diriam na época de Wilde - amor que não se atreve a dizer
seu nome. Não somente se atreveu a dizê-lo, com o tem gritado na vozearia do excesso.
Acaba, poder-se-ia dizer, a festa da orgia homossexual, e com ela termina-se (não era, por
sinal, sua expressão mais chocante e radical?) a revoluçáo sexual que sacudiu o Ocidente
no decorrer deste acidentado século (PERLONGHER, 1993, p. 40).

Com um tom melancólico, o autor se refere a certo esvaziamento da conduta homossexual, que havia conquistado seu espaço de independência no período de revolução sexual nos anos 60 e 70 . Situa a aids, por assim dizer, não no plano exclusivo da doença, mas enquanto fenômeno social. E embora utilize como parâmetro a forte presença da morte por ela causada, refere-se mais a um desaparecimento das práticas associadas à homossexulidade: práticas livres, que há poucos anos havia se libertado dos parâmetros morais, primeiro da Igreja e em seguida da medicina.

Como destaca Pereira (2004), um dos pontos que passa a ser constantemente reafirmado com a epidemia da aids é o discurso acusatório do comportamento promíscuo, especialmente em relação ao comportamento homossexual masculino. 
Trazia à tona o caráter problemático da troca maior de parceiros sexuais, que parecia ter sido superado com a revolução sexual. Desse modo, apagavam-se as heranças das décadas passadas, em que o corpo foi explorado e libertado, para dar luz à censura, a partir das orientaçôes e normas médicas.

Se naquele momento a recente militância homossexual havia conseguido se organizar para reivindicar um status de normalidade, firmando-se na cena social, a aids teria feito desaparecer suas poucas conquistas. O próprio ativismo, com o início da epidemia, enfraquece-se para dar lugar a um ativismo pela aids, uma vez que suas principais lideranças modificam a pauta de reivindicaçôes (FACCHINI, 2002). Ademais, as práticas associadas à homossexualidade masculina, tais como os encontros em bares, saunas e paradas, diluíram-se pelo pânico do chamado "câncer gay". "Arquipélagos de lantejoulas, toucados de penas iridescentes, constelações de purpurinas [...] desaba sob o impacto (é preciso dizê-lo) da morte" (PERLONGHER, 1993, p. 39).

Ocorre, com a emergência da aids, o que o autor chama de "outra volta de parafuso" do próprio dispositivo de sexualidade, nos termos foucaultianos. Não uma volta no sentido de castidade, mas de orientação, através da medicina, de uma sexualidade limpa, desinfetada e transparente, cuja morte é a punição pelo descumprimento. Se a homossexualidade moderna era um personagem relativamente novo, teria vivido, em pouco mais de cem anos, sua glória e ruína. A figura do gay, um dos símbolos da liberação sexual, na avaliação de Pereira (2004, p. 57), é aos poucos substituída, ao longo dos anos 80 , pelo yuppie, "marcado por um estilo mais controlado e por um comportamento mais estilizado, [...] e minimizando a dimensão erótico-sexual da vida cotidiana". Dito de outro modo, o homossexual masculino, em face do perigo da doença que mata, torna-se mais sereno, menos ligado à prática sexual predominante no gueto, para assumir uma postura mais comportada e comprometida com valores sociais, tais como família, emprego e filhos.

Acontece que ao avançarmos duas décadas no novo século, a epidemia letal dos anos 80 deu lugar à cronicidade da aids, através de métodos preventivos e medicamentos que não pararam de se atualizar. Se nos anos iniciais da aids pouco ou quase nada se sabia sobre os recursos terapêuticos, em 1996 o governo brasileiro passou a disponibilizar para os infectados, gratuitamente, pelo recém-constituído Sistema Único de Saúde (SUS), o tratamento com antirretrovirais (ARV). Essa medida muda decisivamente o panorama epidemiológico brasileiro, "pois amplia 
a expectativa e a qualidade de vida das pessoas soropositivas, quando a aids passa a ser considerada doença crônica tratável, e a letalidade da epidemia diminui sensivelmente" (MAKSUD, 2007, p. 27).

Nesse sentido, embora ainda não tenhamos chegado à cura, os avanços com medicamentos ARV sinalizam uma nova volta no parafuso do dispositivo da sexualidade. E se as políticas públicas de prevenção ao HIV/aids ainda caminham em um período de frequentes atualizaçôes, que não escapam de um eixo que liga discursos com saberes e poderes que penetram na atualidade, torna-se interessante questionar quais são as implicaçôes dessas mudanças para a homossexualidade masculina que teria desaparecido nos anos 80 . Diante disso, na próxima seção assumimos o desafio que o próprio Perlongher (1993) nos deixou ao concluir seu texto: continuar a determinar a força e a qualidade da aids (e acrescentamos, dos seus respectivos tratamentos) no devir histórico.

\section{Risco como força individualizadora}

O Brasil, logo após os primeiros anos da descoberta do HIV/aids, tornouse referência mundial no combate ao vírus e a doença, seja com mecanismos de prevenção e/ou tratamento dos já infectados. No histórico que constrói sobre a epidemia, Galvão (2002) cita que já em 1983 foi criado um programa de proteção à doença no estado de São Paulo. Em 1988, o combate ao vírus atingiu o âmbito nacional ao ser chefiado pelo Ministério da Saúde, que começou a distribuição de medicamentos para infecçôes oportunistas causadas pelo HIV, e deu início às primeiras campanhas de prevenção. Nesse sentido, a preocupação em conter a epidemia se tornou prioridade no sistema de saúde, convertendo esta política pública em exemplo a ser seguido por outros países. ${ }^{3}$

Nesse contexto de preocupação com o HIV/aids, o Brasil se tornou o primeiro país da América Latina a iniciar a implementação da chamada profilaxia préexposição ao HIV (PrEP) a partir da publicação da Portaria no 21, de 25 de maio de 2017. Como dito nas páginas introdutórias deste trabalho, trata-se de um esquema medicamentoso distribuído gratuitamente pelo Ministério da Saúde a partir do início de 2018. O efeito esperado desse recurso é a diminuição das chances de adquirir o vírus causador da aids, ou seja, uma medicação de uso contínuo direcionada àqueles que não possuem o HIV no organismo, funcionando como 
mecanismo de prevenção. Em termos técnicos, a PrEP se configura pela combinação de dois antirretrovirais (tenofovir e enticitabina - TDF/FTC - 300/200mg) que deve ser ingerida diariamente. Sua oferta integra a chamada prevenção combinada, ${ }^{4}$ no sentido de constituir um dos diversos procedimentos de caráter preventivo, tais como exames de testagem para o vírus, o uso regular de preservativos, o diagnóstico e tratamento de outras infecçóes sexualmente transmissíveis (ISTs), entre outros.

Publicado pelo Departamento de Vigilância, Prevenção e Controle das IST, do HIV/Aids e das Hepatites Virais, o documento que institucionaliza sua implantação é chamado de Protocolo Clínico de Diretrizes Terapêuticas (PCDT) para PrEP (BRASIL, 2017), e será usado como referência empírica nas análises que desenvolvemos a partir de agora. Seu objetivo é estabelecer os critérios de diagnóstico da doença, o algoritmo de tratamento com as respectivas doses adequadas e os mecanismos para o monitoramento clínico em relação à efetividade do tratamento e à supervisão de possíveis efeitos colaterais. $\mathrm{Na}$ prática, esse documento institucionaliza orientaçóes profissionais, uma vez que se dirige aos que atuam nos serviços públicos de prevenção e controle do HIV/aids. Portanto, a partir das orientaçóes presentes nesse documento, a PrEP passa a ser implementada no país, cumprindo com determinadas finalidades preventivas.

O que torna a PrEP singularmente interessante para este trabalho é o fato de que, se os antirretrovirais, que desde 1996 funcionavam como neutralizadores do vírus entre os indivíduos diagnosticados com HIV, pela primeira vez passam a ser considerados e introduzidos também como mecanismo preventivo. Diante disso, compreendemos que o medicamento inaugura um novo momento para a prevenção do HIV/aids no Brasil; mais do que isso, consideramos que dessa novidade emerge um novo fenômeno social, pois opera não sobre os infectados, mas sobre indivíduos negativados para o vírus.

Além de se tratar de um esquema medicamentoso de uso contínuo, a PrEP se torna ainda mais singular por ser oferecida, até o momento, para os denominados "grupos prioritários":5 "[...] gays e outros homens que fazem sexo com homens (HSH), pessoas transexuais, profissionais do sexo e parcerias sorodiscordantes para o HIV [quando um possui o vírus e o outro não]" (BRASIL, 2017, p. 17). Estaríamos diante de uma estratégia que difere, portanto, de todos os outros métodos preventivos que integram a prevenção combinada por ser o único que mantém como critério inicial de admissão para o tratamento o pertencimento a 
certas categorias de sujeitos. A homossexualidade masculina integra os grupos prioritários por meio das denominaçóes de gay e $\mathrm{HSH},{ }^{6}$ o que nos instiga a pensar sobre os efeitos da PrEP na sua construção social.

Desde que a noção de "grupos de risco" foi abandonada pela epidemiologia, passando pela expressão "comportamento de risco" e, a partir dos anos 90, pela ideia de "indivíduos em situação de vulnerabilidade" (AYRES, 2003), nenhum método preventivo foi direcionado, especificamente, aos homossexuais masculinos. Embora materiais informativos, campanhas de conscientização etc. tivessem certo direcionamento ao longo dos anos, os instrumentos para a prevenção permaneciam disponíveis a todos os públicos nos serviços especializados de saúde. Assim, a disponibilização de preservativos, exames de testagem e, mais recentemente, da profilaxia pós-exposição para infecção pelo $\mathrm{HIV}(\mathrm{PEP})^{7}$ nunca havia respondido a critérios de seletividade estabelecidos em função de identidades específicas.

A justificativa para a oferta da PrEP a grupos considerados prioritários é de que "determinados segmentos populacionais, devido a vulnerabilidades específicas, estão sob maior risco de se infectar pelo HIV, em diferentes contextos sociais e tipos de epidemia" (BRASIL, 2017, p. 13, grifos nossos). Nesse sentido, o conceito de risco segue mantendo uma força determinante em relação à prevenção para o HIV/aids, haja vista que valida a oferta seletiva do medicamento em questão.

Ao examinarmos o risco enquanto linguagem, reconhecemos que o termo denota diversos sentidos, dependendo de quem o emprega e com que finalidade (LUPTON, 1993). Interessa-nos, portanto, analisá-lo como uma construção sociocultural e, diante disso, determinar seus efeitos discursivos. No caso do HIV/aids, a determinação do risco epidemiológico baseada em cálculos probabilísticos não está isenta de transportar significados e formas de categorização moral de identidades e práticas consideradas socialmente desviantes no campo da sexualidade.

Isso pode ser percebido quando o documento que regulariza a utilizaçáo da PrEP afirma que o simples pertencimento aos grupos prioritários não é suficiente para caracterizar indivíduos com risco de exposição frequente ao HIV: "[...] é necessário observar as práticas sexuais, as parcerias sexuais e os contextos específicos associados a um maior risco de infecção" (BRASIL, 2017, p. 14). Quando sugere tal observação, alerta para fatores como a repetição de práticas sexuais sem o uso do preservativo; frequência de relaçóes sexuais com parceiros eventuais; quantidade e diversidade de parcerias sexuais etc., isto é, fatores associados à mesma noção 
de promiscuidade atribuída fortemente aos homossexuais masculinos a partir dos anos 80 (PERLONGHER, 1987; PEREIRA, 2004). Sugerimos, entáo, que essa tecnificação do conceito de risco em relação ao HIV/aids não se refere apenas ao nível biológico do indivíduo, que por praticar certo tipo de relação sexual apresenta maior probabilidade de infecção, na medida em que também responderia às exigências sociais próprias dos padrôes de normalidade socialmente dominantes no plano da sexualidade.

Nessa perspectiva, pode-se aventar a hipótese de que a PrEP estaria possibilitando o retorno da homossexualidade masculina aos consultórios médicos e, mais do que isso, seu reaparecimento como objeto discursivo de problematizaçóes de caráter sanitário e social. Obviamente, assim como escreveu Perlongher (1993) sobre o desaparecimento da homossexualidade, não se trata de afirmar que entre os anos 80 e o momento presente ela havia desaparecido enquanto prática real. Ocorre que, se considerarmos que com a epidemia da aids a homossexualidade havia saído da luz resplandecente da cena pública para dar lugar à figura do aidético moribundo, pode estar retornando hoje por motivos similares àqueles que a fizeram desaparecer.

$\mathrm{O}$ argumento de que os homossexuais seriam grupos prioritários para a PrEP, uma vez que se identifique neles uma frequência significativa de relaçôes sexuais em parcerias diversas torna-os potencialmente passíveis de tratamento. Não de um tratamento no sentido de reversão da sua sexualidade, mas de normalização disciplinar e biopolítica de suas práticas sexuais. Instaura-se, assim, um tipo de disciplinamento que tem origem no preciso momento em que ocorre a adesão ao tratamento, momento a partir do qual se orienta que "uma vez que a PrEP é iniciada, deve-se realizar seguimento clínico e laboratorial a cada três meses" (BRASIL, 2017, p. 31). De maneira mais detalhada, ao iniciar o uso da profilaxia (e para ter acesso ao medicamento), o sujeito em tratamento deve passar por um acompanhamento médico que inclui consultas periódicas e exames laboratoriais. Desse modo, a homossexualidade é situada novamente em um campo documental, em que se registra uma série variada de acontecimentos, tais como rotinas e experiências sexuais. Trata-se de um modo de vigilância que guarda não poucas analogias com aquilo que Foucault (2014) definira como técnica do exame, uma vez que objetiva a homossexualidade "[...] numa rede de anotaçôes escritas; comprometendo-os em toda uma quantidade de documentos que os captam e os fixam" (FOUCAULT, 2014, p. 185). 
Do ponto de vista biopolítico, a PrEP possibilita, ao mesmo tempo e por meio desses registros, exercer funções de controle e administração da população, permitindo que se produzam estimativas e probabilidades sobre as práticas associadas à homossexualidade. Com isso, o Estado passa a contar com novos insumos para a criação de políticas voltadas para o que poderíamos vislumbrar como um novo modo de regulação epidemiológica e, de maneira mais ampla, biopolítica em matéria de HIV/aids. Consequentemente, desenvolvem-se ações que protegem a população, uma vez que o objetivo do tratamento é “[...] reduzir a transmissão do HIV e contribuir para o alcance das metas relacionadas ao fim da epidemia [da aids]" (BRASIL, 2017, p. 9).

O que torna ainda mais interessante o processo de regulação da homossexualidade masculina a partir da PrEP é o caráter opcional de sua utilização. Não se trata de um tratamento coercitivo, mas aparentemente baseado na escolha individual. $\mathrm{O}$ documento que regulamenta sua utilização defende, inclusive, que "[...] as pessoas são autônomas e capazes de fazer escolhas no seu melhor interesse, se tiverem todas as informaçôes necessárias para reduzir seu risco de infecção pelo HIV" (BRASIL, 2017. p. 21). Ocorre que esse princípio de autonomia frente ao tratamento revela o caráter individualizador que a noção de risco carrega consigo quando utilizada para justificar a prevenção por meio da PrEP.

Nos termos de Beck (2011), a individualização se refere aos mecanismos que tornam a percepção dos problemas sociais como individuais. Para o autor, a produção social de riscos resulta em um novo modo de socialização, ou seja, uma nova maneira de relacionamento entre o indivíduo e a sociedade. Ao invés de receber regramentos institucionais prontos, em que apenas seja obrigado a cumpri-lo, o indivíduo é chamado para conduzir e organizar sua vida; não mais de forma obrigatória e vinculada a modelos tradicionais, mas de acordo com um estado de bem-estar. "Individualização significa que a biografia das pessoas se torna independente de determinaçóes pré-fixadas, aberta, disponível e se converte em tarefa a ser desempenhada por cada um" (BECK, 2011, p. 199).

Uma vez que reconheçamos o caráter polissêmico do risco (LUPTON, 1993), ele não somente é utilizado para justificar açôes com a finalidade técnica profissional, mas também de maneira profana, pelos leigos. No caso da homossexualidade masculina, a individualização se dá pelo próprio entendimento desses sujeitos de que suas práticas são potencialmente perigosas, o que demanda que busquem 
formas de prevenção para que se possa continuar exercendo-as. Diferentemente do homossexual que desaparece com a epidemia da aids, pois se vê censurado a abdicar do exercício de uma sexualidade livre devido ao medo da morte, reaparece agora uma homossexualidade que, baseada na aceitação do risco, possibilita o retorno aos antigos anos de liberdade a partir da sujeição disciplinar e biopolítica à PrEP. A noção de risco, portanto, é o que permite que a homossexualidade possa voltar a exacerbar-se na intensidade de seus próprios impulsos sexuais.

Poder-se-ia admitir que isso já vinha ocorrendo com a inserção do preservativo como método preventivo. Contudo, mesmo se desconsiderássemos as implicaçôes culturais da introdução do látex no domínio do prazer, nenhum outro método preventivo foi capaz de situar a homossexualidade masculina novamente sob a tutela da medicina de forma permanente. Paradoxalmente, a única maneira de se afastar da condição de potencialmente perigoso é se reconhecendo como tal, permitindo que a própria medicina discipline o corpo para que, novamente, seja libertado para experimentar o gozo sem medo ou culpa.

Não se pode atribuir à individualização, portanto, um significado de independência ou emancipação. Pelo contrário: a individualização dos riscos sobre o HIV/aids supõe a utilização de técnicas para administrar os indivíduos que se submetem à PrEP. Concordamos, portanto, com Mitjavila e Jesús (2004), quando afirmam que em nome dos riscos, justificam-se intervençôes capazes de vigiar, orientar, controlar, julgar indivíduos e os setores de população que não conseguem ou que opôem resistência à construção de certos "estilos de vida saudáveis ou corretos".

No caso da homossexualidade, esses "estilos de vida" não implicam mais punir os excessos da libertinagem ou liberação sexual, tal como fizeram a Igreja Católica ou a medicina até o século XX, mas de dar início ao reaparecimento de um novo tipo de homossexual. Liberado do domínio do pecado e da doença, ele agora é convidado a assumir sua prática perigosa e a entregá-la para que a medicina a administre, receitando o tratamento que ameniza seus sintomas. Em contraposição, recebe o direito de voltar à festa do apogeu, em um festejo em plena luz do dia.

\section{Considerações finais}

Ao longo deste trabalho, procuramos demonstrar como a homossexualidade masculina vem sendo organizada desde que saiu das sombras da sodomia para caminhar pelas calçadas da cena pública. Para isso, recapitulamos como, desde o 
século XX, a medicina se apropria de suas práticas para exercer certas funções de normalização. Se inicialmente o objetivo foi, de forma fracassada, convertê-la a um modelo heterossexual, com a emergência da aids, desenvolve-se um novo modo de controlar seus impulsos, sem que isso implique prescrever a castidade. Náo se trata de questionar os avanços em termos epidemiológicos que as estratégias de prevenção em relaçáo ao HIV/aids proporcionam, tampouco defender uma total autonomia frente às doenças que afetam os corpos na individualidade. $\mathrm{O}$ que buscamos apontar é como a implantação de novas formas de prevenção, tais como a profilaxia préexposição ao HIV, não somente garantem a manutençáo da vida, haja vista que impedem novas infecçóes e as cruéis mortes pela aids, como situa novamente a homossexualidade masculina no campo disciplinar dos consultórios médicos.

Se, como atesta Foucault (2017), a medicina assumiu o lugar da religião e, diante disso, o domínio de saber científico passou a incidir sobre as sexualidades, talvez uma das mais afetadas ainda seja aquela inicialmente considerada como anormal. O que não quer dizer, é claro, que esse novo padrão de regulação biopolítica da sexualidade responda aos antigos esquemas de punição e censura. Mas sim que o funcionamento do risco como dispositivo central da gestão biopolítica do HIV/aids estaria promovendo novas formas de individualização social ao permitir e incentivar que os próprios homossexuais se reconheçam como problema e entreguem suas biografias para que sejam administradas sob a tutela do Estado e da profissão médica.

A partir da implantação da PrEP, reaparece a figura do homossexual cujo desaparecimento foi observado por Perlongher (1993). Contudo, ressurge sob novos contornos. Reaparece agora um homossexual que deixa de ser visto essencialmente como pecador, doente e/ou estigmatizado pela sua associação direta com a aids. Contudo, para que obtenha o direito de continuar exercendo seus desejos em plena luz do dia, é convidado a individualizar-se, isto é, assumir-se como potencialmente perigoso e, por decisão própria, situar-se no campo documental do tratamento preventivo. $^{8}$

\section{Referências}

ABREU, C. F. Os dragóes não conhecem o Paraíso. São Paulo: Companhia das Letras, 1988.

AYRES, J. R. C. M. et al. O conceito de vulnerabilidade e as práticas de saúde: novas perspectivas e desafios. In: CZERESNIA, D.; FREITAS, C. M. Promoção da saúde: conceitos, reflexóes, tendências. Rio de Janeiro, Fiocruz, 2003, p. 121-144. 
BECK, U. Sociedade de risco: rumo a uma outra modernidade. São Paulo: Editora 34, 2011.

BESSA, M. S. Os perigosos: autobiografias \& Aids. Rio de Janeiro: Aeroplano, 2002.

BRASIL. Ministério da Saúde. Secretaria de Políticas de Saúde. Coordenação Nacional de DST e Aids. Protocolo clínico e diretrizes terapêuticas para Profilaxia Préexposição (PrEP) de risco à infecção pelo HIV. Brasília: Ministério da Saúde, 2015.

. Ministério da Saúde. Secretaria de Políticas de Saúde. Coordenação Nacional de DST e Aids. Protocolo clínico e diretrizes terapêuticas para Profilaxia Préexposição (PrEP) de risco à infecção pelo HIV. Brasília: Ministério da Saúde, 2017.

. Ministério da Saúde. Secretaria de Vigilância em Saúde. Departamento de Vigilância, Prevenção e Controle das Infecçôes Sexualmente Transmissíveis, do HIV/Aids e das Hepatites Virais. Protocolo Clínico e Diretrizes Terapêuticas para Profilaxia Pós-exposição (PEP) de risco à infecção pelo HIV, IST e Hepatites Virais. Brasília: Ministério da Saúde, 2018.

. Ministério da Saúde. Secretaria de Vigilância em Saúde. Departamento de Doenças de Condiçóes Crônicas e Infecçóes Sexualmente Transmissíveis. Protocolo Clínico e Diretrizes Terapêuticas para Atenção Integral às pessoas com Infecçôes sexualmente transmissiveis (IST). Brasília: Ministério da Saúde, 2019.

DANIEL, H.; PARKER, R. Aids: a terceira epidemia. São Paulo: Iglu, 1991.

FACCHINI, R. "Sopa de Letrinhas"? Movimento homossexual e produção de identidades coletivas nos anos 90: um estudo a partir da cidade de São Paulo. 2002. Dissertação (Mestrado em Antropologia) Departamento de Antropologia do IFCH, UNICAMP, Campinas, 2002.

FOUCAULT, M. Em defesa da sociedade: curso no Collège de France (1975-1976). São Paulo: Martins Fontes, 2010.

. História da sexualidade 1: A vontade de saber. Rio de Janeiro/São Paulo: Paz \& Terra, 2017.

. Vigiar e punir: história da violência nas prisões. Petrópolis: Vozes, 2014.

FRY, P.; MACRAE, E. O que é homossexualidade. São Paulo: Brasiliense, 1985.

GALVÃO, J. 1980-2001: uma cronologia da epidemia de HIVIAIDS no Brasil e no mundo. Rio de Janeiro: ABIA, 2002.

LUPTON, D. Risk as moral danger: the social and political functions of risk discourse in Public Health. International Journal of Health Services, n. 23, p. 425-435, 1993.

MAKSUD, I. Casais sorodiscordantes: conjugalidade, práticas sexuais e HIVIAids. 2007. $271 \mathrm{f}$. Tese (Doutorado em Saúde Coletiva) - Instituto de Medicina Social, Universidade do Estado do Rio de Janeiro. 
MITJAVILA, M.; JESÚS, C. Globalização, modernidade e individualização social. Revista Katálysis, n. 7, p. 69-79, 2004.

PEREIRA, C. A. M. O Impacto da Aids, a afirmação da "cultura gay" e a emergência do debate em torno do "masculino" - fim da homossexualidade? In: RIOS, L. F. et al. Homossexualidade: produção cultural, cidadania e saúde. Rio de Janeiro: ABIA, 2004, p. 52-62.

PERLONGHER, N. O. O desaparecimento da homossexualidade. In: DANIEL, H. et al. SaúdeLoucura 3. São Paulo: Hucitec, 1993, p. 39-45.

. O que é aids. São Paulo: Brasiliense, 1987.

\section{Notas}

${ }^{1}$ Aponta Foucault (2010) que o poder disciplinar centra-se no corpo, produzindo efeitos individualizantes, cujo objetivo é tornar os indivíduos dóceis e úteis. $\mathrm{Na}$ contramão, mas não de maneira excludente, a regulamentação biopolítica vislumbra não o corpo isolado, mas a vida: "uma tecnologia que agrupa os efeitos de massas próprios de uma população, que procura controlar a série de eventos fortuitos que podem ocorrer numa massa viva [...]" (FOUCAULT, 2010, p. 209).

${ }^{2}$ Embora os atuais boletins epidemiológicos apontem que o primeiro caso de aids no país tenha ocorrido em 1980, essa foi uma informação revista posteriormente. Como destaca Galvão (2002), o primeiro Boletim Epidemiológico AIDS, no seu formato impresso, começou a circular somente em 1987.

${ }^{3}$ Abrimos um parêntese para destacar que, em 17 de maio de 2019, sob a gestão do presidente Jair Bolsonaro e do ministro da Saúde Luiz Henrique Mandetta, o governo brasileiro anunciou, por meio do Decreto no 9.795, que o Departamento das IST, do HIV/Aids e das Hepatites Virais (DIAHV) passaria a se chamar Departamento de Doenças de Condiçốes Crônicas e Infecções Sexualmente Transmissíveis (DDCCI). Embora tenha afirmado que a resposta brasileira ao HIV não será prejudicada, a mudança vem preocupando entidades, ativistas e pesquisadores na área, que temem pela redução de investimentos em relação ao HIV/aids no país. Ao adotarmos uma perspectiva teórica que não admite a neutralidade das práticas discursivas, problematizamos a invisibilizaçấo do termo HIV/aids na reformulaçấo do departamento. Mesmo que não haja reflexos diretos nas políticas públicas, esse apagamento discursivo tende a repercutir negativamente na forma que o Brasil vem enfrentando o vírus e a doença desde os anos 80 .

${ }^{4}$ O Ministério da Saúde chama de prevenção combinada o conjunto de ferramentas de prevenção ao HIV/ aids, que incluem exames de testagem para infecções sexualmente transmissíveis (IST), tratamentos com antirretrovirais e imunizaçóes diversas, além do que chama redução de danos e gerenciamentos de vulnerabilidades (BRASIL, 2017).

${ }^{5}$ Diversos órgãos internacionais de Saúde Global, bem como outros protocolos clínicos envolvendo o HIV/aids (BRASIL, 2018; 2019) integram esses grupos também na denominação "populações-chave". Para manter uma fidelidade ao documentário empírico analisado neste texto (BRASIL, 2017), seguiremos utilizando a expressão "grupos prioritários". Ambas as expressões se referem aos segmentos populacionais que apresentam prevalência de infecçôes por HIV superior à média nacional, que é de $0,4 \%$. Essas "populaçóes-chave" são: gays e outros HSH; pessoas trans; pessoas que usam álcool e outras drogas; pessoas privadas de liberdade e trabalhadoras(es) sexuais. A partir da análise do PCDT para a PrEP, nota-se que o que difere os "grupos prioritários" das "populaçôes-chave", em um primeiro momento, é que a primeira 
expressão, presente em Brasil (2017), não inclui pessoas que usam álcool e outras drogas e pessoas privadas de liberdade. Devido ao recorte deste trabalho, essa distinção não será problematizada, o que não impede que tal questão volte a ser discutida em trabalhos futuros.

${ }^{6}$ A sigla HSH fez parte de uma estratégia epidemiológica que busca contemplar a especificidade do contingente de homens que se relacionavam sexualmente com pessoas do mesmo sexo, mas nem por isso se reconhecem como homossexuais.

${ }^{7}$ Embora a profilaxia pós-exposição para infecção pelo HIV (PEP) mantenha como critério de utilização a "exposição com risco significativo de transmissão do HIV" (BRASIL, 2015, p. 12), esse medicamento nâo utiliza o pertencimento a nenhuma categoria populacional como exigência para sua administraçâo.

${ }^{8}$ L. Barp foi responsável pela concepçáo e elaboração do manuscrito; coleta e análise de dados; redação, revisão e aprovação da versão final. M. Mitjavila responsabilizou-se pela concepção e elaboração do manuscrito; redação, revisão e aprovação da versão final. 


\section{Abstract}

The male homosexuality reappearance in $H I V$ infection prevention strategies: reflections on the PrEP implementation in Brazil

This paper takes its starting point the text by Nestor Perlongher, entitled $O$ desaparecimento da homossexualidade [The disappearance of homosexuality], depicting an emptying of male homosexual identity with the emergence of aids, and proposes a new reading about the pre-exposure prophylaxis (PrEP) implementation by the public health system in Brazil. Distributed from early 2018 and considered as one of the newest HIV/aids prevention measures, PrEP is a continuous antiretroviral therapy aimed for subjects who have not been infected with the virus. Taking as an empirical reference the Clinical Protocol of PrEP Therapeutic Guidelines, we identified how, from the notion of risk, prophylaxis enables the return of homosexuality to doctors' offices and, furthermore, operates as a discursive object of sanitary and social problematizations. Thus PrEP produces a new homosexual category, linked to disciplinary and biopolitical technologies, which rely on the individualization and accountability of individuals for self-care.

> Keywords: homosexuality; HIV; PrEP; risk; individualization. 